\title{
The link between HIV/AIDS and violence among young adults: A study in Udupi, Karnataka
}

Background: Violence is a major public health problem which affects the community and threatens the life of people. Objectives: To estimate the prevalence and different forms of violence among HIV positive young adults taking antiretroviral therapy (ART) in Udupi district. Materials and Methods: A cross-sectional study was carried out among HIV positive young adults (18-35 years) who were aware of their status. The participants were selected from ART Centre of Udupi district adopting convenience sampling. Data were collected from 200 young HIV positive young adults using a predesigned, pre-tested self-administered questionnaire. Results: The overall prevalence of domestic violence was $14.5 \%$ and was found to be more among females $(17.6 \%)$ as compared to males $(6.9 \%)$. This difference was statistically significant among gender with a $P$-value $<0.05$. Among the various forms of violence the prevalence of physical violence was found to be $14.5 \%$ with significant difference among gender. Among females who experienced physical violence, husband was perpetrator in $76 \%$ cases and among males, parents/relatives as the perpetrator in $75 \%$ cases. Around $8.5 \%$ of females had experienced sexual violence and husband was perpetrator in $50 \%$ of the cases followed by relatives and friend/acquaintance. Conclusion: Physical and sexual violence was found to be more in female HIV positive patients as compared to males. The presence of violence among HIV positive young adults especially among the females demands for the concerted efforts at combating underlying factors leading to violence among this vulnerable group of HIV positive young adults.

Key words: ART, HIV positive, physical and sexual violence, young adults

Department of Public Health,

${ }^{2}$ Statistics, Manipal University,

${ }^{1}$ Senior Medical Officer,

ART Centre, Udupi District

Hospital, Karnataka, India

Address for the Correspondence:

Dr. Lena Ashok,

Department of Public Health, Manipal University, Madhav Nagar, Manipal - 576 104,

Karnataka, India.

E-mail: lenaashok@gmail.com

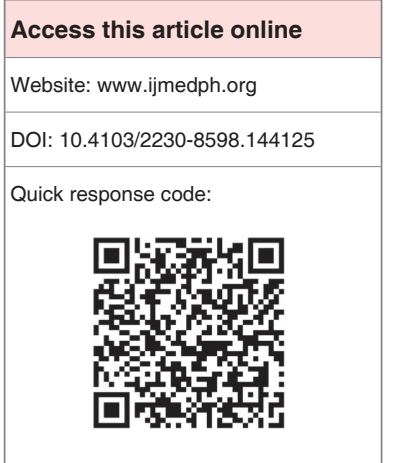

\section{INTRODUCTION}

Violence is a major public health problem that affects the communities and threatens the life. More than 1.6 million people die worldwide as a result of violence. ${ }^{[1]}$ Most of the times the risk of violence is higher in the domestic setting and ultimately concealed from public health aspect. Many who live with violence assume that it is an intrinsic part of their lives.

According to World Health Organization (WHO) violence is "the intentional use of physical force or power, threatened or actual, against oneself, another person, or against a group or community that either results in or has a high likelihood of resulting in injury, death, psychological harm, or deprivation."[2] Whereas domestic violence is defined as a pattern of abusive behaviors by one or both partners in an intimate relationship such as marriage, dating, family, friends or cohabitation. ${ }^{[3]}$ People experience various types of domestic violence like physical, sexual and psychological abuse. ${ }^{[2]}$

Globally, there were 34 million people including 3.4 million children below 15 years living with HIV in 2010. ${ }^{[6]}$ There were 2 million adolescents (aged 10-19) and 5 million young adults (15-24 years) living with HIV in $2009^{[7]}$ and the epidemic varies between countries. ${ }^{[8]}$

Among the HIV positive people, women are basically at a higher risk of violence from their partner. A study from South Africa reported that women with violent partners are more than $50 \%$ likely to be HIV positive as compared to other women. ${ }^{[9]}$ Also, a study conducted in Tanzania showed that young HIV positive women reported intimate partner violence as compared to the other women. ${ }^{[10]}$ 
Research has identified that there is an association between domestic violence and HIV/AIDS and it has emerged as a major public health concern since victims are at high risk for adverse health outcomes, including HIV/AIDS, STDs, alcohol and drug abuse. There is a dearth of literature on violence among people living with HIV and most of the available studies were carried out in the American and African setting. Udupi district is one among the high prevalence area for the HIV/AIDS in India and since there are no studies done, the present study was conducted to explore the threat of violence and assess the different forms and magnitude of violence among people living with HIV/AIDS.

\section{Objectives}

- $\quad$ To estimate the prevalence of violence among HIV positive young adults taking antiretroviral therapy (ART) in Udupi district, Karnataka.

- To assess the magnitude and different forms of violence among HIV positive young adults.

\section{MATERIALS AND METHODS}

A cross-sectional study was done at the Antiretroviral Therapy Centre, Udupi district, Karnataka between February 2013 to July 2013 using semi-structured self-administered questionnaire among HIV positive young adults in age group of 18-35 years (National Youth Policy of India). ${ }^{[1]}$ Questionnaire was modified based on relevant literature and modified to suit the cultural context before data collection.

The participants included in the study were aware about their positive status and were residents of Udupi district. Permission was taken from the District surgeon of the District hospital of Udupi district and also the ethical approval obtained from Manipal University Institutional ethical committee. The written informed consent was obtained from each participant before giving the questionnaire.

The required number of respondents to be included in the study were calculated using the sample size estimation formula for prevalence. Since the literature review could not identify an appropriate prevalence rate for domestic violence among HIV positive young adults, $50 \%$ was considered with $7 \%$ absolute precision for calculation of sample size.

$$
\begin{aligned}
& \frac{Z_{\alpha}^{2} \mathrm{p}(1-\mathrm{p})}{\mathrm{d}^{2}} \\
& \mathrm{n}=(1.96 * 1.96 * 0.5 * 0.5) /(0.07)^{2} \\
& \quad=0.9604 / 0.0049 \\
& =196 \\
& \quad \approx 200
\end{aligned}
$$

Thus the minimum sample size required for the study was 200 . The participants were selected by using convenient sampling method. HIV positive young adults who visited ART Centre during data collection period and willing to give informed consent were included in the study.
The final questionnaire was translated to the local language so that participants will understand the questions better before they answer it. The translated questionnaire was pretested.

\section{Statistical analysis}

The data were analyzed with the help of SPSS vs.15.0. The descriptive data were analyzed with frequency and percentages. The chi-square test was used to find the association between the various aspects of violence \& self-esteem and gender.

\section{RESULTS}

Among 200 participants, 71\% were females while 29\% males. Since convenience sampling technique was adopted, the study showed the visit of female HIV positive persons more in the ART Centre as compared to the male HIV positive persons [Table 1].

The age distribution as per the stages of young people according to National Youth Policy of India showed that $58.5 \%$ participants belonged to age group of $31-35$ years, $32.5 \%$ from $26-30$ years,

\begin{tabular}{|c|c|c|c|}
\hline \multirow[t]{2}{*}{ Characteristics } & $\begin{array}{c}\text { Male } \\
(N=58)\end{array}$ & $\begin{array}{c}\text { Female } \\
(N=142)\end{array}$ & $\begin{array}{c}\text { Total } \\
(N=200)\end{array}$ \\
\hline & $N(\%)$ & $N(\%)$ & $N(\%)$ \\
\hline \multicolumn{4}{|l|}{ Age distribution (in years) } \\
\hline$\leq 20$ & $3(5.2)$ & $3(2.1)$ & $6(3)$ \\
\hline $21-25$ & $4(6.9)$ & $8(5.6)$ & $12(6)$ \\
\hline $26-30$ & $11(19)$ & $54(38)$ & $65(32.5)$ \\
\hline $31-35$ & $40(69)$ & $77(54.2)$ & $117(58.5)$ \\
\hline \multicolumn{4}{|l|}{ Marital status } \\
\hline Single/Unmarried & $36(62.1)$ & $9(6.3)$ & $45(22.5)$ \\
\hline Married & $22(37.9)$ & $73(51.4)$ & $95(47.5)$ \\
\hline Widow & 0 & $53(37.3)$ & $53(26.5)$ \\
\hline Divorced & 0 & $1(0.7)$ & $1(0.5)$ \\
\hline Separated & 0 & $5(3.5)$ & $5(2.5)$ \\
\hline Living together & 0 & $1(0.7)$ & $1(0.5)$ \\
\hline \multicolumn{4}{|l|}{ Education } \\
\hline Illiterate & $2(3.4)$ & $14(9.9)$ & $16(8)$ \\
\hline Lower primary & $11(19)$ & $34(23.9)$ & $45(22.5)$ \\
\hline Higher primary & $12(20.7)$ & $46(32.4)$ & $58(29)$ \\
\hline Secondary & $24(41.4)$ & $38(26.8)$ & $62(31)$ \\
\hline Higher secondary/PUC & $6(10.3)$ & $7(4.9)$ & $13(6.5)$ \\
\hline Graduation & $3(5.2)$ & $3(2.1)$ & $6(3)$ \\
\hline \multicolumn{4}{|c|}{ Total Family income (in INR) } \\
\hline$\leq 3000$ & $8(13.8)$ & $49(34.5)$ & $57(28.5)$ \\
\hline $3001-6000$ & $21(36.2)$ & $45(31.7)$ & $66(33)$ \\
\hline $6001-9000$ & $12(20.7)$ & $9(6.3)$ & $21(10.5)$ \\
\hline$>9000$ & $12(20.7)$ & $10(7.1)$ & $22(11)$ \\
\hline No response & $5(8.6)$ & $29(20.4)$ & $34(17)$ \\
\hline
\end{tabular}
$6 \%$ from $21-25$ years and 3\% from 18-20 years. The same age distribution was observed among both genders. Majority of male $(69 \%)$ and female $(54.2 \%)$ participants belonged to the age group of $31-35$ years [Table 1]. 
Majority $(93.5 \%)$ of the participants belong to Hindu religion, while $4.5 \%$ were Muslims and $2 \%$ Christians. Of the total 200 participants $47.5 \%$ were from Udupi taluk, $40.5 \%$ from Kundapura taluk and $12 \%$ from Karkala taluk, Udupi District.

Among all participants, $47.5 \%$ were married while $26.5 \%$ were widows and $22.5 \%$ single/unmarried. Among male participants, $62.1 \%$ were unmarried whereas among female participants only $6.3 \%$ were unmarried [Table 1 ].

There was wide variation observed regarding the educational level among the participants. Around 8\% participants were Illiterate compared to $92 \%$ who had formal education. Majority of participants (31\%) had secondary level of education. Among the study population $61.5 \%$ had family income less than INR 6000 per month; while only $21.5 \%$ had more than INR 6000 per month and about $17 \%$ participants had not stated their family income [Table 1].

Around $14.5 \%$ of the participants experienced violence and this was found to be more among males was $6.9 \%$ and in females $17.6 \%$ which was statistically significant with $P$-value of $<0.05$.

The various forms of violence observed were physical and sexual violence. A total of $14.5 \%$ experienced physical violence among the participants this was found to be with statistically significant difference among male $(6.9 \%)$ and female $(17.6 \%)$ participants with $P$-value of $<0.05$ [Table 2].

It was observed that among females who experienced physical violence, husband was perpetrator in $76 \%$ of cases, followed by friends/acquaintance in $12 \%$ of cases, parents/relatives in $8 \%$ of cases and steady boyfriend in $4 \%$ of cases. Among male participants who experienced physical violence, majority $(75 \%)$ of them experienced from their parents/relative and 25\% from their friend/acquaintance [Table 2].

Regarding the participants experience on sexual violence in their life, $8.5 \%$ females reported to have experienced sexual violence while none of the male participants reported the same. Of the female participants who experienced sexual violence, husband was the perpetrator in $50 \%$ of cases followed by relatives $25 \%$ and friend/ acquaintance $25 \%$. Of these females only about $25 \%$ had discussed this issue and preferred family members, close friend and service provider for discussion of this issue [Table 3].

The participants were asked about the worries of various aspects of life. The most common issues participants were worried about was their HIV positive status (69.5\%), looks of other people toward them $(66 \%)$, people finding out about their HIV positive status (63.5\%), infecting someone else with HIV (53\%), disclosing status to their friends $(48.5 \%)$, unable to find partner $(38.5 \%)$, having sexual relationship (34\%), dumped by partner (33.5\%), becoming or making someone pregnant $(20.5 \%)$, and forceful sex (12.5\%). All these aspects were found to be statistically significant among male and females with $P$-value $<0.05$.

\begin{tabular}{|c|c|c|c|}
\hline \multirow[t]{2}{*}{$\begin{array}{l}\text { Physical violence } \\
\text { Indicators }\end{array}$} & $\begin{array}{c}\text { Male } \\
(N=58)\end{array}$ & $\begin{array}{c}\text { Female } \\
(N=142)\end{array}$ & $\begin{array}{c}\text { Total } \\
(N=200)\end{array}$ \\
\hline & $N(\%)$ & $\overline{N(\%)}$ & $N(\%)$ \\
\hline \multicolumn{4}{|l|}{ Ever been physically abused } \\
\hline Yes & $4(6.9)$ & $25(17.6)$ & $29(14.5)$ \\
\hline No & $54(93.1)$ & $117(82.4)$ & $171(85.5)$ \\
\hline If yes, Perpetrator & $(n=4)$ & $(n=25)$ & $(n=29)$ \\
\hline Husband/Wife & 0 & $19(76)$ & $19(65.5)$ \\
\hline Parent/Relative & $3(75)$ & $2(8)$ & $5(17.2)$ \\
\hline Steady boyfriend/Girlfriend & 0 & $1(4)$ & $1(3.4)$ \\
\hline Friend/Acquaintance & $1(25)$ & $3(12)$ & $4(13.8)$ \\
\hline $\begin{array}{l}\text { Discussed this problem } \\
\text { with anyone }\end{array}$ & $(n=4)$ & $(n=25)$ & $(n=29)$ \\
\hline Yes & $2(50)$ & $18(72)$ & $20(69)$ \\
\hline No & $2(50)$ & $7(28)$ & $9(31)$ \\
\hline If yes, with whom & $(n=2)$ & $(n=18)$ & $(n=20)$ \\
\hline Family member & $2(100)$ & $6(33.3)$ & $8(40)$ \\
\hline Close friend & 0 & $11(61.1)$ & $11(55)$ \\
\hline Other & 0 & $1(5.6)$ & $1(5)$ \\
\hline
\end{tabular}

\begin{tabular}{lc}
$\begin{array}{l}\text { Table 3: Distribution of participants on experience } \\
\text { of sexual violence* }\end{array}$ \\
\hline Sexual violence indicators & $\begin{array}{c}\text { Female } \\
(\mathbf{N}=142)\end{array}$ \\
\cline { 2 - 2 } & $\mathbf{N}(\%)$ \\
\hline Ever been sexually abused & \\
Yes & $12(8.5)$ \\
No & $130(91.5)$ \\
If yes, Perpetrator & $(n=12)$ \\
Husband/wife & $6(50)$ \\
Relative & $3(25)$ \\
Friend/Acquaintance & $3(25)$ \\
Discussed this problem with anyone & $(n=12)$ \\
Yes & $3(25)$ \\
No & $9(75)$ \\
If yes, with whom & $(n=3)$ \\
Family member & $1(33.33)$ \\
Close friend & $1(33.33)$ \\
Service provider/counselor & $1(33.33)$ \\
\hline
\end{tabular}

*None of the male participants had experienced sexual violence

Also $62.5 \%$ were worried about being mistreated/rejected by friends and $54 \%$ about their development of body was not as fast as their friends. This was not found to be statistically significant among male and female as $P$ value was greater than 0.05 .

\section{DISCUSSION}

The prevalence of physical violence observed among HIV positive young adults in Udupi was around $14.5 \%$. The proportion of physical violence among females was $17.6 \%$ and among males was $6.9 \%$. A study in India conducted by Chandrasekaran $e t$ al. showed that $42 \%$ of female participants reported that they experienced violence, of whom 29\% reported physical violence and 69\% reported psychological abuse while it was $31 \%$ in a study conducted 
by Birungi et al. ${ }^{[12]}$ in Kenya (31\%). The reason for the lower prevalence of violence in present study could be due to under reporting of the issue by the participants.

The findings reported in the study conducted by Birungi et al..$^{[12]}$ in Kenya showed no difference in prevalence of physical violence among male and female HIV positive adolescents (15-19 years). The study conducted by Iliyaz et al. ${ }^{[13]}$ in Kano on HIV positive women stated that the risk of domestic violence was more among the women as compared to men, where prevalence of violence among women was $22 \%$ which was similar to the present study.

In majority of the cases, the perpetrator of physical violence was found to husband $(76 \%)$ in females and parents/relatives $(75 \%)$ in males. A study conducted by Aryal et al. ${ }^{[14]}$ in Nepal among HIV positive women found husband (45\%) as perpetrator for physical violence in majority of the cases. Also a study conducted by the Ramachandra et al. ${ }^{[15]}$ in 2010 in Nigeria found that almost threefourth of the sample $(73 \%)$ reported lifetime violence from their partner and $20 \%$ reported current abuse.

In present study those who had experienced physical violence when asked whether they discussed this issue with anyone, about $69 \%$ participants stated that they had discussed the issue with others. Among participants who discussed, more than half (55\%) of them discussed with close friends followed by family members (40\%). Similar findings were observed by Birungi, et al. ${ }^{[12]}$ in Kenya in 2011 where around $31 \%$ participants had experienced physical violence in their life and about $65 \%$ of them had discussed this problem and most of them discussed with either family member, close friends or service providers.

In the present study, none of the male participants had experienced sexual violence whereas $8.5 \%$ of females had experienced it. The study conducted by Birungi et al. ${ }^{[13]}$ in Kenya among HIV positive adolescents found the higher prevalence of sexual violence among males $(13 \%)$ and females $(16 \%)$ as compared to present study. Prevalence of sexual violence is found to be low in the present study could be due to under reporting as it is a sensitive issue.

The participants in the present study reported to be worried about various aspects of life. The most common issues they were worried about, their HIV positive status (69.5\%), looks of other people towards them $(66 \%)$, people finding out about their HIV positive status (63.5\%), infecting someone else with HIV (53\%), disclosing status to their friends $(48.5 \%)$, unable to find partner $(38.5 \%)$, having sexual relationship (34\%), dumped by partner (33.5\%), becoming or making someone pregnant $(20.5 \%)$, and forceful sex (12.5\%). All these aspects were found to be statistically significant among male and females with $P$-value $<0.05$.

Similar findings were observed in the study conducted by Birungi $\mathrm{H}$, et al. ${ }^{[11]}$ in Kenya where $85 \%$ of participants were worried about infecting others with HIV, 66\% getting someone pregnant, 64\% disclosing HIV status, people coming to know their HIV status
(64\%), being forced to do things they did not want (63\%), and having sex $(57 \%)$. On the other hand a greater proportion of women were worried about having sex, being coerced into doing things that they did not want, or being rejected by friends as compared to males.

\section{CONCLUSION}

The life of HIV positive young adults is compromised due to the prevailing disease condition; the present study was conducted to explore the domestic violence among HIV positive young adults. The prevalence of physical violence among HIV positive young adults was found to be $14.5 \%$ with higher proportion in females. Similarly the sexual violence was found only among the females (8.5\%). This showed the vulnerability of the women suffering from HIV which has to be managed properly. In most of the females who suffered from violence, husband was the perpetrator which proved that the Intimate partner violence is still increasing in our country. They had not discussed these issues very commonly with others and kept it hidden which makes them more vulnerable. The HIV positive people were worried about various aspects of life such as looks of other people being identified by other people and mistreated by friends, which supports the presence of fear and stigma among the HIV positive people that is still existing in our community.

The presence of violence among HIV positive people especially among the females demands concerted efforts at combating underlying factors leading to violence among this vulnerable group. The capacity of existing counselors needs to be enhanced to understand the issues of violence among HIV positive people so that young HIV positive adults can openly talk about these issues with counsellors. These strategies will be useful in addressing the issue of violence through counseling. Another major issue found in the study was "HIV positive young adults still living with fear and anxiety. Organizing training on positive living and regular reinforcing of positive messages can help HIV positive young adults to cope with fear and anxiety.

\section{REFERENCES}

1. World Report on violence and health: Summary. Geneva: World Health Organization, 2002. Available from: http://www.who.int/violence_injury_ prevention/violence/4th_milestones_meeting/publications/en/index.html [Last cited on 2013 July 21].

2. World Health Organization. Defining violence, Geneva, Switzerland, Definition of violence by World Health Organisation; 2010. Available from: http://www.who.int/violenceprevention/approach/definition/en/[Last cited on 2013 July 21].

3. United Nations Convention on the Elimination of all forms of Discrimination Against women, CEDAW. Available from: http://www.un.org/womenwatch/ daw/cedaw/text/ecconvention.html [Last cited on 2013 July 25].

4. Garcia-Moreno C, Jansen HA, Ellsberg M, Heise L, Watts $\mathrm{CH}$; WHO Multi-country Study on Women's Health and Domestic Violence against Women Study Team. Prevalence of intimate partner violence: Findings from the WHO multi-country study on women's health and domestic violence. Lancet 2006;368:1260-9.

5. Silverman JG, Decker MR, Saggurti N, Balaiah D, Raj A. Intimate partner violence and HIV infection among married Indian women. JAMA 2008;300:703-10.

6. Global HIVIAIDS response: Epidemic update and health sector progress towards universal access. Joint United Nationals Programme on HIV/ AIDS (UNAIDS); Progress report [Serial online] 2011. Available from: 
http://www.unaids.org/en/media/unaids/contentassets/documents/ unaidspublication/2011/20111130_ua_report_en.pdf. [Last cited on 2012 Nov 29].

7. Fifth stock taking report: Children and AIDS. Unite for Children and Unite against AIDS. Joint United Nations programme on HIVIAIDS (UNAIDS); 2010. Report No.: UNICEF/NYHQ2006-1376/Piroz. Available from: http:// www.unicefusa.org/assets/pdf/1-Children-and-AIDS-Fifth-StocktakingReport_EN_18Nov.pdf [Last cited on 2010 Nov 29].

8. Global HIVIAIDS response: Epidemic update and health sector progress towards universal access. Joint United Nationals Programme on HIVIAIDS (UNAIDS); Progress report] 2011. Available from: http://www.unaids.org/en/media/unaids/contentassets/documents/ unaidspublication/2011/20111130_ua_report_en.pdf [Last cited on 2012 Nov 29].

9. Dunkle KL, Jewkes RK, Brown HC, Grey GE, Mclntryre JA, Harlow SD. Gender-based violence, relationship power, and risk of HIV infection in women attending antenatal clinics in South Africa. Lancet 2004;363:1415-21.

10. Maman S, Mbwambo JK, Hogan NM, Kilonzo GP, Campbell JC, Weiss E, et al. HIV-Positive Women Report More Lifetime Partner Violence: Findings From a Voluntary Counseling and testing Clinic in Dares Salaam, Tanzania. Am J Public Health 2002;92:1331-7.

11. Ministry of Youth Affairs and Sports, Government of India. Exposure Draft of national Youth Policy 2012 (NYP 2012) Available from: http:// planipolis.iiep.unesco.org/upload/Youth/India/India_draft_National_ youth_policy_2012.pdf [Last cited on 2013 Jan 12].

12. Birungi $H$, Obare F, Namwebya HJ, Mohammed M, Gitau M, Makumi M. Sexual and reproductive health needs of adolescents living with HIV in Kenya. APHIA II OR Project in Kenya. Nairobi, Kenya: Population Council [Serial online] 2011 Available from: http://www.popcouncil.org/pdfs/2011RH_ APHIAll_SRHHIVPositiveAdol.pdf [Last cited on 2013 May 20].
13. Iliyasu Z, Abubakar I, Babushani M, Galadanci HS. Domestic violence among women living with HIVIAIDS in Kano, Northern Nigeria. Afr J Reprod Health 2011;15:41-50.

14. Aryal N, Regmi PR, Mudwari NR. Violence against women living with HIV: A cross-sectional study in Nepal. Glob J Health Sci 2012;4:117-25.

15. Ramachandra S, Yonas MA, Silvester AJ, Burke JG. Intimate Partner Violence among HIV positive persons in an Urban clinic. AIDS Care 2010;22:1536-43.

16. Birungi H, Mugisha JF, Nyombi J, Obare F, Evelia H, Nyinkavu HJ. Sexual and reproductive health needs of adolescents perinatally infected with HIV in Uganda. Frontiers Final Report. Washington, DC: Population Council [Serial online] 2008 Available from: http//www.popcouncil.org/ pdfs/frontiers/FR_FinalReports/UgandaHIV.pdf [Last cited on 2013 May 20].

17. WHO report highlights violence against women as a 'global health problem of epidemic proportions'. Available from: http://www.who.int/ mediacentre/news/releases/2013/violence_against_women_20130620/ en/[Last cited on 2013 July 24].

18. National AIDS Control Organization (NACO). Department of AIDS Control. Ministry of Health and Family Welfare, Government of India. HIV monitoring (Treatment for AIDS) [Serial online] 2007. Available from: http://www.nacoonline.org/NACO/National_AIDS_Control_Program/ Services_for_Prevention/[Last cited on 2013 June 20].

How to cite this article: Yadav N, Kamath R, Ashok L, Shetty B, Hegde BM, Dhar M, et al. The link between HIVIAIDS and violence among young adults: A study in Udupi, Karnataka. Int J Med Public Health 2014;4:486-90.

Source of Support: Nil, Conflict of Interest: None declared.

\section{Staying in touch with the journal}

1) Table of Contents (TOC) email alert Receive an email alert containing the TOC when a new complete issue of the journal is made available online. To register for TOC alerts go to www.ijmedph.org/signup.asp.

\section{2) RSS feeds}

Really Simple Syndication (RSS) helps you to get alerts on new publication right on your desktop without going to the journal's website. You need a software (e.g. RSSReader, Feed Demon, FeedReader, My Yahoo!, NewsGator and NewzCrawler) to get advantage of this tool. RSS feeds can also be read through FireFox or Microsoft Outlook 2007. Once any of these small (and mostly free) software is installed, add www. ijmedph.org/rssfeed.asp as one of the feeds. 